ISSN 1980-5098

\title{
ANÁLISE FITOGEOGRÁFICA DA FLORA ARBUSTIVO-ARBÓREA EM ECÓTONO NO PLANALTO DA BODOQUENA, MS, BRASIL
}

\author{
PHYTOGEOGRAPHIC ANALYSIS OF SHRUB AND TREE FLORA IN AN ECOTONAL AREA IN \\ THE BODOQUENA PLATEAU, MS, BRAZIL
}

\author{
Carmen Beatriz Reiss Zavala ${ }^{1}$ Shaline Séfara Lopes Fernandes ${ }^{2}$ Zefa Valdivina Pereira ${ }^{3}$ \\ Sandro Menezes Silva ${ }^{4}$
}

\begin{abstract}
RESUMO
O estabelecimento de prioridades na conservação dos ecossistemas terrestres remete à necessidade de conhecimento acerca da diversidade destes ambientes, especialmente no bioma Cerrado e suas zonas de transição florística, já que se encontram em elevado estágio de degradação. Com este cenário, este estudo objetivou realizar o inventário florístico de um fragmento florestal sobre área de tensão ecológica no Planalto da Bodoquena, MS, Brasil, e avaliar suas relações fitogeográficas com outras florestas estacionais e cerrados do Centro-Oeste e Sudeste do Brasil. Foram amostradas 102 parcelas contíguas de $10 \times 10 \mathrm{~m}$ $\left(100 \mathrm{~m}^{2}\right)$. O critério de inclusão foi o perímetro a altura do peito (PAP) $\geq 15 \mathrm{~cm}$. Na análise de similaridade florística foi aplicado o coeficiente de Sorensen, adotando-se o método de ligação pela média de grupo (UPGMA), em que se calculou o grau de similaridade de 26 listas florísticas. Das 96 espécies ocorrentes neste levantamento, 91 foram identificadas em nível específico, e, destas, 80,2\% (73) foram encontradas em um ou mais estudos das áreas analisadas, com maior ocorrência em Floresta Estacional Decidual (FED) (54), seguida por Floresta Estacional Semidecidual (FES) (47) e cerradão (46). Os resultados mostraram agrupamento da área de estudo com as FED de Minas Gerais em nível de 30\%, revelando baixa similaridade. Devido à baixa similaridade florística entre as áreas analisadas, estas são caracterizadas pela sua elevada diversidade beta.
\end{abstract}

Palavras-chave: cerrado; floresta estacional; transição florística; similaridade.

\section{ABSTRACT}

Setting priorities in the conservation of terrestrial ecosystems refers to the need for knowledge about the diversity of environments, especially in the Cerrado biome and its floristic transition zones, already in high stage of degradation. With this scenario, this study aimed to carry out a floristic inventory of a forest fragment on ecological tension in Bodoquena Plateau, MS, Brazil, and assess their phytogeographical relationships with other surveys of seasonal forests and savannas in the Midwest and Southeast regions of Brazil. For this, 102 contiguous plots of $10 \times 10 \mathrm{~m}\left(100 \mathrm{~m}^{2}\right)$ were sampled. The inclusion criterion was the perimeter at breast height $(\mathrm{PBH}) \geq 15 \mathrm{~cm}$. For floristic similarity analysis, the coefficient of Sorensen was applied, adopting the unweighted pair group method with arithmetic mean (UPGMA), with the determination of

1 Bióloga, MSc., Técnico em Assuntos Educacionais, Universidade Federal de Mato Grosso do Sul, Campus de Bonito, Rodovia Bonito-Três Morros, Km 0, Zona Rural, CEP 79290-000, Bonito (MS), Brasil. cbreiss@hotmail.com

2 Agrônoma, MSc., Doutoranda em Recursos Naturais, Universidade Estadual de Mato Grosso do Sul, Rua Elsei Fuginaka, 2495, Altos do Indaiá, CEP 79823-500, Dourados (MS), Brasil. shaline_sefara@hotmail.com

3 Bióloga, Dr ${ }^{\mathrm{a}}$., Professora Adjunto III, Faculdade de Ciências Biológicas e Ambientais, Universidade Federal da Grande Dourados, Rua Reinaldo Bianche, 1040, Parque Alvorada, CEP 79823-381, Dourados (MS), Brasil. zefapereira@ufgd.edu.br

4 Biólogo, Dr., Professor Adjunto, Coordenador do Curso de Ciências Biológicas - Bacharelado da Universidade Federal da Grande Dourados, Rua Amael Pompeu Filho, 505, Parque Alvorada, CEP 79823-370, Dourados (MS), Brasil.sandromenezes@ufgd.edu.br 
the level of similarity of 26 floristic lists. Of the 96 species occurring in this survey, 91 were identified at species level, and of these, $80.2 \%$ (73) were found in one or more studies of the analyzed areas with higher occurrence in seasonal deciduous forest (SDF) (54), followed by seasonal semideciduous forest (SSF) (47) and forested savannah (46). The results showed clustering of the study area with the FED of Minas Gerais in level of 30\%, revealing low similarity. Due to low floristic similarity between the analyzed areas, these are characterized by their high beta diversity.

Keywords: cerrado; seasonal forest; floristic transition; similarity.

\section{INTRODUÇÃO}

Toda a flora terrestre está condicionada por fatores ambientais tais como o clima, as características químicas e físicas do solo, além da ação da fauna e dos distúrbios antrópicos (OLIVEIRA-FILHO; RATTER, 1995; OLIVEIRA-FILHO; JARENKOW; RODAL, 2006; SCARIOT; SEVILHA, 2005; CAMPOS et al., 2006), criando variações florísticas e fisionômicas ao longo do território. A composição e a distribuição da flora do Cerrado também são bastante heterogêneas, tornando a sua conservação complexa e dependente da identificação de grupos fitogeográficos em nível local e regional (BRASIL, 2002). Ao serem consideradas asinterfaces com outros biomas, a relevância é ainda maior, pois os contrastes entre estes formam paisagens mais diversas (FELFILI; SOUSA-SILVA; SCARIOT, 2005).

Sob este enfoque, Oliveira-Filho, Jarenkow e Rodal (2006) relataram que atualmente a ocorrência das florestas estacionais tropicais e subtropicais da América do Sul segue um gradiente florístico que possui contatos e limites desde florestas ombrófilas até formações abertas, como cerrados e campos, ou os extremos climáticos de caatingas (tropical) e florestas chaquenhas (subtropical). Silva e Bates (2002) estimaram que $24 \%$ do bioma Cerrado seja ocupado pela transição savana-floresta. Contudo, em virtude dos processos de degradação ambiental que vêm ocorrendo com grande velocidade e intensidade, e que colocam estes ecossistemas sob ameaça de extinção (SCARIOT; SEVILHA, 2005), o conhecimento da sua biodiversidade se faz urgente para propor medidas de controle e conservação.

A região da Serra da Bodoquena está situada na borda sudoeste do bioma Cerrado, no limite com o Pantanal Sul-mato-grossense, constituindo-se em um planalto inclinado de maciço rochoso com porção mais baixa a oeste, no sentido da planície pantaneira, com elevações montanhosas de até $800 \mathrm{~m}$ de altura (DIAS, 2000; SALLUN FILHO; KARMANN, 2007; SALLUN FILHO et al., 2009). É caracterizada como área de tensão ecológica (IBGE, 2004), definida pelo contato entre savanas e florestas estacionais (SILVA; BATES, 2002), as quais coexistem sob o mesmo regime climático e em grande proximidade geográfica (PENNINGTON; PRADO; PENDRY, 2000).

Segundo Oliveira-Filho e Ratter (2000), as Florestas Estacionais Deciduais e Semideciduais estão amplamente distribuídas no município de Bonito, na região da Serra da Bodoquena, sobre manchas de solos calcários. As formações deciduais calcífilas, presentes ao longo da porção sul do Planalto, notadamente no Parque Nacional da Serra da Bodoquena, estão inseridas no núcleo Missiones, cujas florestas estacionais foram consideradas relictos de uma formação florestal mais extensa, que teria existido durante o período de máximo glacial, funcionando como uma rota de conexão entre as caatingas, as florestas semidecíduas paranaenses e as florestas dos flancos orientais andinos (PRADO; GIBBS, 1993; OAKLEY; PRADO, 2011).

Considerando este contexto, os estudos florísticos sob o enfoque biogeográfico revelam o padrão de distribuição das espécies, o que permite o direcionamento das ações de conservação da biodiversidade, incorporando informações necessárias ao estabelecimento de prioridades. Para tanto, este estudo objetivou levantar a flora arbustivo-arbórea de um fragmento de floresta ecotonal no Planalto da Bodoquena, município de Bonito - MS, e analisá-lo fitogeograficamente em relação às áreas de cerrados e florestas estacionais da região Centro-Oeste e Sudeste do Brasil. 


\section{MATERIAL E MÉTODOS}

\section{Área de estudo e levantamento florístico}

A área amostrada está inserida na propriedade do Parque das Cachoeiras, município de Bonito MS, com o fragmento de 48 ha de extensão de mata distribuída sobre morros contíguos, contornado por pastagens de pecuária extensiva e tendo como ponto inicial as coordenadas $56^{\circ} 30^{\prime} 30^{\prime \prime} \mathrm{W}$ e $21^{\circ} 0^{\prime} 30^{\prime} \mathrm{S}$. Dias (2000) classificou esta região como Unidade dos Morros Disjuntos, cuja topografia é irregular e a vegetação apresenta-se em fragmentos isolados sobre os morros.

Foi selecionado um dos morros com localização central no fragmento, sendo sua altitude de 400 $\mathrm{m}$ no topo e $330 \mathrm{~m}$ na base, constituindo-se em área de interflúvio com solo bem drenado. Os solos são rasos e formados sobre o mosaico litológico e geomorfológico, diferindo ao longo do gradiente. Foram identificados o Chernossolo Rêndzico e o Neossolo Litólico (SANTOS et al., 2006) em associação, ambos de textura média, em relevo ondulado e de pouca profundidade.

O clima é estacional, do tipo Aw pela classificação de Köppen, com período chuvoso de outubro a março e seco de abril a setembro, e precipitação média anual de 1.400 a $1.600 \mathrm{~mm}$. As temperaturas médias anuais estão entre $22^{\circ} \mathrm{C}$ e $26^{\circ} \mathrm{C}$; a média das mínimas fica entre $18^{\circ} \mathrm{C}$ e $20^{\circ} \mathrm{C}$, de maio a agosto, e das máximas entre $27^{\circ} \mathrm{C}$ e $32^{\circ} \mathrm{C}$, nos demais meses do ano (BAPTISTA-MARIA et al., 2009). Há elevada deciduidade na comunidade arbórea, estimada entre $50 \%$ até $70 \%$ no período de estiagem prolongada.

A vegetação arbustivo-arbórea foi amostrada em 102 parcelas contíguas de $10 \times 10 \mathrm{~m}\left(100 \mathrm{~m}^{2}\right)$. O critério de inclusão foi o perímetro a altura do peito (PAP) $\geq 15 \mathrm{~cm}$. Durante as incursões foram coletadas amostras do material botânico, as quais foram herborizadas e as exsicatas incorporadas ao Herbário da Universidade Federal da Grande Dourados - UFGD. A classificação taxonômica seguiu o sistema APG III (ANGIOSPERM PHYLOGENY GROUP, 2009) e a atualização de táxons foi realizada mediante consulta ao banco de dados na Lista de Espécies da Flora do Brasil (JARDIM BOTÂNICO DO RIO DE JANEIRO, 2014) e em The Plant List (2013).

\section{Análise fitogeográfica}

As terminologias adotadas estão de acordo com o IBGE (2012) para Floresta Estacional Decidual (FED) e Semidecidual (FES), porém, por convenção regionalista, foram consideradas as terminologias para o bioma Cerrado de Ribeiro e Walter (2008), em que a Savana recebeu a denominação regional "cerrado", das quais derivam o cerrado sensu lato, que inclui Savana Florestada (cerradão), e o cerrado sensu stricto com a Savana Arbórea Aberta. Ainda, a Savana Estépica Florestada foi tratada por vegetação de chaco.

A escolha das fisionomias florestais incluídas na análise é decorrente da variedade florística presente na região, que é influenciada pelos domínios Cerrado e Mata Atlântica. Dessa forma, 25 estudos fitossociológicos realizados em FED, FES, cerradão e em cerrado sensu stricto fazem parte da análise (Figura 1; Tabela 1), totalizando 26 estudos com o presente levantamento. As matrizes de presença/ausência incluíram somente os táxons identificados em nível de espécie para o componente arbustivo-arbóreo.

$\mathrm{Na}$ análise de similaridade foi empregado o método UPGMA, mensurada pelo coeficiente de Sorensen, caracterizado pela análise multivariada de presença/ausência de espécies, cuja matriz de dados foi montada em planilha eletrônica e a geração do dendrograma realizada no software FITOPAC 2.1.2 (SHEPHERD, 2010).

\section{RESULTADOS E DISCUSSÃO}

O levantamento florístico chegou a uma listagem de 96 espécies, sendo quatro identificadas em nível de gênero e uma em nível de família (Tabela 2), caracterizando elevada riqueza no fragmento estudado.

Foram incluídos os 91 táxons em nível específico na análise de similaridade e, com os demais levantamentos, a lista compilada chegou a 534 espécies após atualização taxonômica. Suas ocorrências nas 26 listas florísticas, separadas por fitofisionomia (Tabela 2), permitiram encontrar 18 espécies exclusivas da área de estudo, das quais, 15 foram registradas em florestas ribeirinhas, mata ciliar e cerrado na região 

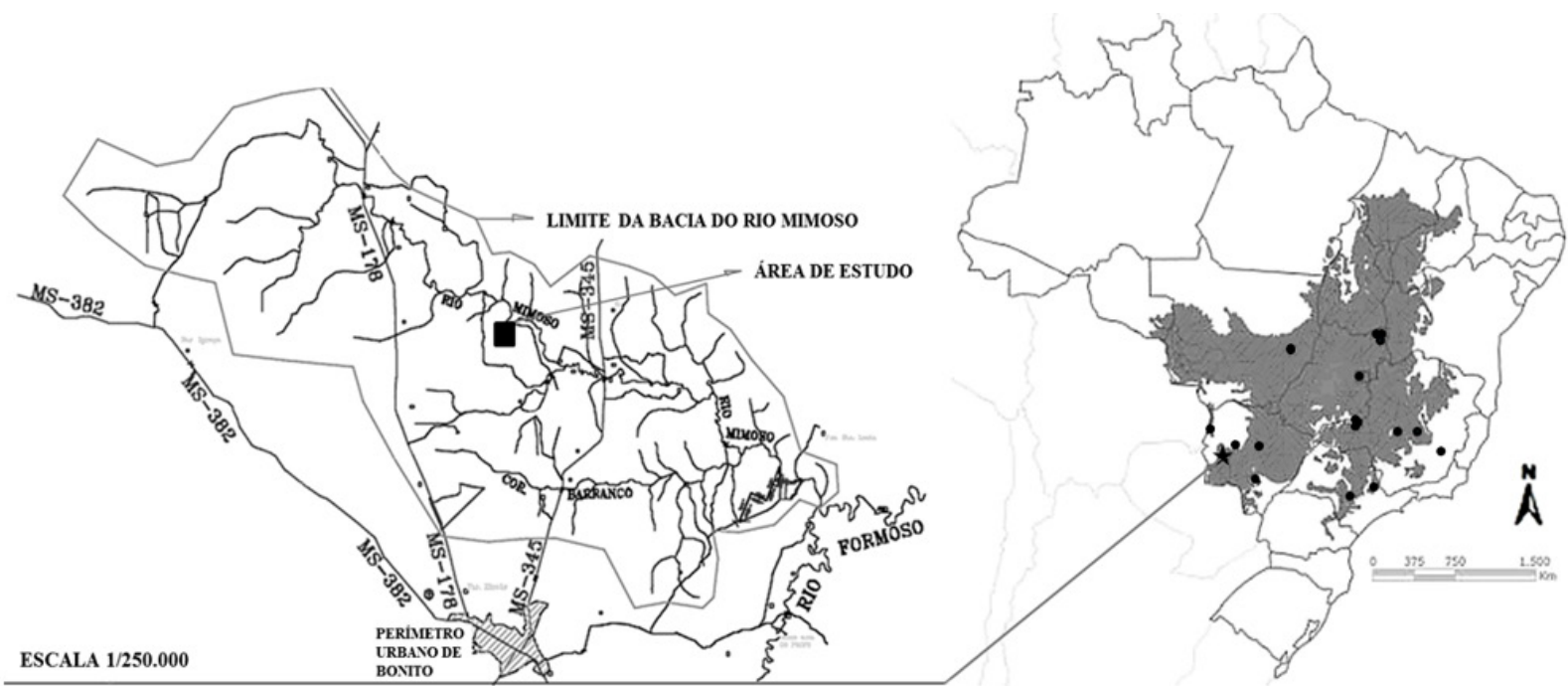

FIGURA 1: Mapa de localização da área de estudo na bacia hidrográfica do rio Mimoso, Bonito - MS e a distribuição dos 26 levantamentos florísticos incluídos na análise de similaridade. A área marcada em cinza indica a localização do bioma Cerrado, Brasil.

FIGURE 1: Location map of the study area in the basin of river Mimoso, Bonito - MS, and the distribution of 26 floristic surveys included in the analysis of similarity. The gray area indicates the location of the Cerrado biome, Brazil.

(BATTILANI; SCREMIN-DIAS; SOUZA, 2005; BAPTISTA-MARIA et al., 2009; RAMOS; SARTORI, 2013), com exceção de Geoffroea spinosa, Guapira hirsuta e Qualea cordata, sendo que, destas, as duas primeiras têm ocorrência registrada no Estado (JARDIM BOTÂNICO DO RIO DE JANEIRO, 2014) e a última é considerada uma típica espécie savânica (PINHEIRO; MONTEIRO, 2006).

Vale destacar que trinta e três espécies apresentaram ampla distribuição, aparecendo em três ou quatro unidades fitofisionômicas. Tiveram maior número de registros Astronium fraxinifolium, Myracrodruon urundeuva, Tapirira guianensis, Tabebuia aurea, Anadenanthera colubrina, Casearia sylvestris e Qualea grandiflora, que estiveram presentes de 13 a 16 estudos (50\% a 61,5\% de ocorrência).

Durigan e Ratter (2006) descreveram a situação que encontraram para definição das fisionomias vegetais em estudos no estado de São Paulo, afirmando que chega a ser impossível, nas áreas ecotonais, classificar a vegetação em cerrado ou floresta atlântica, com ocorrência de espécies de ambos os domínios em proporções variadas. Os mesmos autores também defenderam que as propriedades edáficas são o principal fator determinante da composição florística e estrutura das comunidades nas áreas transicionais, tendo sido constatados gradientes de fertilidade e de retenção hídrica do solo ao longo das áreas estudadas, pois as condições climáticas são as mesmas para ambas as fisionomias. Assim, para compreender a complexidade florística local, deve-se também levar em conta a heterogeneidade geomorfológica da área estudada, a qual é geradora de diferentes tipos de solos. O Projeto Radambrasil (ARAÚJO et al., 1982) identificou nas proximidades do local de estudo, na rodovia MS 345 (antiga MT 738) que liga Bonito a Aquidauana, grande variedade litológica do Grupo Cuiabá, com presença de rochas dos tipos sericita-quartzo, xistos, filitos, ardósias, calcários e dolomitos, estes dois últimos ocorrendo em afloramentos, na forma de lentes, intercalados com xistos e filitos.

No conjunto das 25 listas florísticas comparadas a este estudo, obteve-se que 80,2\% (73) das espécies aqui amostradas estavam presentes em uma ou mais áreas, a maioria apresentou ocorrência em outras FED (54), seguida por FES (47) e cerradão (46), com menor ocorrência no cerrado sensu stricto (28) (Figura 2). Isoladamente, as FED tiveram o maior número de espécies exclusivas (8) deste estudo e, conjuntamente, as florestas estacionais englobaram o maior número de exclusivas (26) e total (67) das espécies locais. As fisionomias de cerrado (CD e CSS) incluíram 47 espécies, sendo duas exclusivas de CD 
TABELA 1: Estudos fitossociológicos incluídos na análise de similaridade florística de um fragmento de floresta ecotonal no Planalto da Bodoquena, Bonito - MS, Brasil.

TABLE 1: Phytosociological studies included in the analysis of floristic similarity of a fragment of ecotonal forest in Bodoquena Plateau, Bonito, MS, Brazil.

\begin{tabular}{|c|c|c|c|c|c|c|c|}
\hline Código & Fisionomia & Autor/Ano & Local & N. spp & Área (ha) & Amostragem & Inclusão $(\mathrm{cm})$ \\
\hline Estudo & Ecótono & Presente estudo & Bonito - MS & 96 & 1,02 & $102 \mathrm{P}(10 \mathrm{x} 10 \mathrm{~m})$ & $\mathrm{PAP} \geq 15$ \\
\hline FED/MS1 & FEDTB & $\begin{array}{c}\text { Lima, Damasceno- } \\
\text { Júnior e Tanaka (2010) }\end{array}$ & Corumbá - MS & 34 & & 80 pontos $(\mathrm{Q})$ & $\mathrm{CAP} \geq 15$ \\
\hline FED/MS2 & FEDSM & $\begin{array}{l}\text { Lima, Damasceno- } \\
\text { Júnior e Tanaka (2010) }\end{array}$ & Corumbá - MS & 33 & & 78 pontos $(\mathrm{Q})$ & $\mathrm{CAP} \geq 15$ \\
\hline FED/GO1 & FED & $\begin{array}{l}\text { Nascimento, Felfili e } \\
\text { Meirelles (2004) }\end{array}$ & Monte Alegre - GO & 52 & 1 & $25 \mathrm{P}(20 \times 20 \mathrm{~m})$ & $\mathrm{DAP} \geq 5$ \\
\hline FED/GO2 & FED & Silva e Scariot (2003) & São Domingos - GO & 36 & 1 & $25 \mathrm{P}(20 \times 20 \mathrm{~m})$ & $\mathrm{DAP} \geq 5$ \\
\hline FED/GO3 & FED & Silva e Scariot (2004) & São Domingos - GO & 51 & 1 & $25 \mathrm{P}(20 \times 20 \mathrm{~m})$ & $\mathrm{DAP} \geq 5$ \\
\hline FED/GO4 & FED & $\begin{array}{c}\text { Carvalho e Felfili } \\
\text { (2011) }\end{array}$ & Iaciara - GO & 45 & 1 & $25 \mathrm{P}(20 \times 20 \mathrm{~m})$ & $\mathrm{DAP} \geq 5$ \\
\hline FED/MG1 & FED & $\begin{array}{l}\text { Siqueira, Araújo e } \\
\text { Schiavini (2009) }\end{array}$ & "Funil 1" - MG & 64 & 1,2 & $60 \mathrm{P}(10 \times 20 \mathrm{~m})$ & $\mathrm{CAP} \geq 15$ \\
\hline FED/MG2 & FED & $\begin{array}{l}\text { Siqueira, Araújo e } \\
\text { Schiavini (2009) }\end{array}$ & "Funil 2" - MG & 46 & 1,2 & $60 \mathrm{P}(10 \times 20 \mathrm{~m})$ & $\mathrm{CAP} \geq 15$ \\
\hline $\mathrm{FED} / \mathrm{SP}$ & FED & $\begin{array}{c}\text { Ivanauskas e Rodrigues } \\
\text { (2000) }\end{array}$ & Piracicaba - SP & 54 & 0,4 & $43 \mathrm{P}(10 \times 10 \mathrm{~m})$ & $\mathrm{PAP} \geq 15$ \\
\hline FES/MS1 & FES & Arruda e Daniel (2007) & Dourados - MS & 76 & & $9 \mathrm{~T}(1680 \mathrm{~m} \operatorname{lin})$ & $\mathrm{CAP} \geq 15$ \\
\hline FES/MS2 & FES & Salis et al. (2012) & $\begin{array}{c}\text { Pantanal Nhecolândia } \\
\text { - MS }\end{array}$ & 44 & 0,7 & $\begin{array}{l}4 \mathrm{~T}(150 \times 10 \mathrm{~m} \\
200 \times 10 \mathrm{~m})\end{array}$ & $\mathrm{DAP} \geq 5$ \\
\hline FES/MG1 & FES & Martins et al. (2003) & Viçosa - MG & 49 & 0,5 & $20 \mathrm{P}(10 \times 25 \mathrm{~m})$ & $\mathrm{DAP} \geq 4.8$ \\
\hline FES/MG2 & FES & Marangon et al. (2007) & Viçosa - MG & 146 & 1 & $40 \mathrm{P}(25 \times 10 \mathrm{~m})$ & $\mathrm{CAP} \geq 15$ \\
\hline $\mathrm{FES} / \mathrm{SP}$ & FES & $\begin{array}{c}\text { Ivanauskas, Rodrigues e } \\
\text { Nave (1999) }\end{array}$ & Itatinga - SP & 97 & 0,42 & $42 \mathrm{P}(20 \times 5 \mathrm{~m})$ & $\mathrm{DAP} \geq 4.8$ \\
\hline $\mathrm{CD} / \mathrm{MS} 1$ & Cerradões (6) & Salis et al. (2006) & $\begin{array}{c}\text { Pantanal Nhecolândia } \\
\text { - MS }\end{array}$ & 86 & & $30 \mathrm{QC}(\mathrm{x} 6=180)$ & $\mathrm{CAP} \geq 15$ \\
\hline $\mathrm{CD} / \mathrm{MS} 2$ & Cerradão & $\begin{array}{l}\text { Camilotti, Pagotto e } \\
\text { Araujo (2011) }\end{array}$ & Bandeirantes - MS & 82 & 1 & $16 \mathrm{P}(25 \times 25 \mathrm{~m})$ & $\mathrm{DAP} \geq 5(\mathrm{H} \geq 3 \mathrm{~m})$ \\
\hline $\mathrm{CD} / \mathrm{MS} 3$ & Cerradão & Bueno et al. (2013) & Campo Grande - MS & 61 & 1 & $10 \mathrm{P}(5 \times 20 \mathrm{~m})$ & $\mathrm{DAP} \geq 4.77$ \\
\hline $\mathrm{CD} / \mathrm{MG} 1$ & Cerradão & Souza et al. (2010) & Paraopeba - MG & 61 & 0,3 & $30 \mathrm{P}(10 \times 10 \mathrm{~m})$ & $\mathrm{CAP} \geq 10$ \\
\hline $\mathrm{CD} / \mathrm{MG} 2$ & $\begin{array}{l}\text { Cerradão } \\
\text { mesotrófico }\end{array}$ & $\begin{array}{l}\text { Rodrigues e Araújo } \\
\text { (2013) }\end{array}$ & Araguari - MG & 90 & 1 & $25 \mathrm{P}(20 \times 20 \mathrm{~m})$ & $\mathrm{CAP} \geq 15$ \\
\hline $\mathrm{CD} / \mathrm{MG} 3$ & $\begin{array}{l}\text { Cerradão } \\
\text { distrófico }\end{array}$ & $\begin{array}{c}\text { Rodrigues e Araújo } \\
\text { (2013) }\end{array}$ & Uberlândia - MG & 83 & 1 & $25 \mathrm{P}(20 \times 20 \mathrm{~m})$ & $\mathrm{CAP} \geq 15$ \\
\hline $\mathrm{CD} / \mathrm{MT}$ & $\begin{array}{l}\text { Cerradão } \\
\text { distrófico }\end{array}$ & $\begin{array}{l}\text { Marimon Junior e } \\
\text { Haridasan (2005) }\end{array}$ & Nova Xavantina - MT & 77 & 0,5 & $50 \mathrm{P}(10 \times 10 \mathrm{~m})$ & $\mathrm{DAS} \geq 5$ \\
\hline CSS/MS1 & $\begin{array}{c}\text { Cerrado } \\
\text { sensu stricto }\end{array}$ & $\begin{array}{c}\text { Lehn, Alves e } \\
\text { Damasceno Junior } \\
(2008)\end{array}$ & Corumbá - MS & 31 & 0,4 & $64 \mathrm{P}(5 \times 12.5 \mathrm{~m})$ & $\mathrm{CAS} \geq 13$ \\
\hline CSS/MT2 & $\begin{array}{c}\text { Cerrado } \\
\text { sensu stricto }\end{array}$ & $\begin{array}{l}\text { Marimon Junior e } \\
\text { Haridasan (2005) }\end{array}$ & Nova Xavantina - MT & 77 & 0,5 & $50 \mathrm{P}(10 \times 10 \mathrm{~m})$ & $\mathrm{DAS} \geq 5$ \\
\hline $\mathrm{CSS} / \mathrm{MG}$ & $\begin{array}{c}\text { Cerrado } \\
\text { sensu stricto }\end{array}$ & $\begin{array}{l}\text { Saporetti Junior, Meira } \\
\text { Neto e Almado (2003) }\end{array}$ & Abaeté - MG & 85 & 0,3 & $15 \mathrm{P}(10 x 20 \mathrm{~m})$ & $\mathrm{DAS} \geq 10$ \\
\hline $\mathrm{CSS} / \mathrm{DF}$ & $\begin{array}{c}\text { Cerrado } \\
\text { sensu stricto }\end{array}$ & $\begin{array}{c}\text { Assunção e Felfili } \\
\text { (2004) }\end{array}$ & APA Paranoá - DF & 54 & 1 & $10 \mathrm{P}(20 \times 50 \mathrm{~m})$ & $\operatorname{DAS}(30 \mathrm{~cm}) \geq 5$ \\
\hline
\end{tabular}

Em que: FED $=$ Floresta Estacional Decidual; FES $=$ Floresta Estacional Semidecidual; $\mathrm{CD}=$ cerradão; $\mathrm{CSS}=$ cerrado sensu stricto; FEDTB = floresta estacional decidual de terras baixas; FEDMS = floresta estacional decidual submontana; Estados do Centro-Oeste: GO, MS, MT; Estados do Sudeste: MG, SP; Distrito Federal: DF; P = parcelas; $\mathrm{T}=$ transectos; $\mathrm{m}$ lin = metros lineares; $\mathrm{PAP}=$ perímetro a altura do peito; $\mathrm{CAP}=$ circunferência a altura do peito; $\mathrm{DAP}$ = diâmetro a altura do peito; $\mathrm{H}=$ altura. 
TABELA 2: Lista de espécies arbustivo-arbóreas registradas no Planalto da Bodoquena, Bonito - MS, Brasil, e sua ocorrência em mais 25 levantamentos florísticos. Em que: FED = Floresta Estacional Decidual; FES = Floresta Estacional Semidecidual; CD = cerradão; CSS = cerrado sensu stricto; presença indicada por " $\mathrm{x}$ " e número total de áreas de ocorrência (TA), incluindo a área de estudo; Reg - número de registro no Herbário da UFGD.

TABLE 2: List of woody species recorded in Bodoquena Plateau, Bonito, MS, Brazil, and its occurrence in more 25 floristic surveys. Wherein: FED = deciduous forest; FES = semideciduous seasonal forest, $C D=$ cerradão; $C S S=$ cerrado sensu stricto; presence indicated by " $x$ " and total number of the areas of occurrence (TA), including the study area; Reg - registration number in the Herbarium of UFGD.

\begin{tabular}{|c|c|c|c|c|c|c|c|c|}
\hline \multirow{2}{*}{ Família } & \multirow{2}{*}{ Espécie } & \multirow{2}{*}{ Nome popular } & \multicolumn{6}{|c|}{ Ocorrência } \\
\hline & & & FED & FES & $\mathrm{CD}$ & CSS & TA & Reg. \\
\hline \multirow{3}{*}{ Anacardiaceae } & Astronium fraxinifolium Schott & gonçalo & $\mathrm{x}$ & $\mathrm{x}$ & $\mathrm{x}$ & $\mathrm{x}$ & 16 & 5105 \\
\hline & Myracrodruon urundeuva Allemão & aroeira & $\mathrm{x}$ & $\mathrm{x}$ & $\mathrm{x}$ & $\mathrm{x}$ & 16 & 5106 \\
\hline & Tapirira guianensis Aubl. & peito-de-pombo & $\mathrm{x}$ & $\mathrm{x}$ & $\mathrm{x}$ & $\mathrm{x}$ & 13 & 5107 \\
\hline \multirow{3}{*}{ Apocynaceae } & Aspidosperma cylindrocarpon Müll. Arg. & peroba & $\mathrm{x}$ & $\mathrm{x}$ & & & 4 & 5108 \\
\hline & Aspidosperma subincanum Mart. & guatambú & $\mathrm{x}$ & $\mathrm{x}$ & $\mathrm{x}$ & $\mathrm{x}$ & 9 & 5109 \\
\hline & Aspidosperma tomentosum Mart. & peroba-do-cerrado & $\mathrm{x}$ & & $\mathrm{x}$ & $\mathrm{x}$ & 9 & 5110 \\
\hline Araliaceae & Dendropanax cuneatus (DC.) Decne. \& Planch. & maria-mole & & $\mathrm{x}$ & & & 3 & 5111 \\
\hline \multirow{3}{*}{ Arecaceae } & Acrocomia aculeata (Jacq.) Lodd. ex Mart. & bocaiúva & $\mathrm{x}$ & $\mathrm{x}$ & $\mathrm{x}$ & & 6 & 5112 \\
\hline & Attalea phalerata Mart. ex Spreng. & bacuri & $\mathrm{x}$ & $\mathrm{x}$ & $\mathrm{x}$ & & 4 & 5113 \\
\hline & Syagrus romanzoffiana (Cham.) Glassman & pindó & $\mathrm{x}$ & $\mathrm{x}$ & & & 5 & 5114 \\
\hline \multirow{6}{*}{ Bignoniaceae } & Handroanthus heptaphyllus (Vell.) Mattos & ipê-roxo & & & & & 1 & 5115 \\
\hline & Handroanthus impetiginosus (Mart. ex DC.) Mattos & ipê-roxo & $\mathrm{x}$ & $\mathrm{x}$ & $\mathrm{x}$ & & 9 & 5116 \\
\hline & Handroanthus ochraceus (Cham.) Mattos & ipê-amarelo & $\mathrm{x}$ & $\mathrm{x}$ & $\mathrm{x}$ & $\mathrm{x}$ & 9 & 5117 \\
\hline & Jacaranda cuspidifolia Mart. & jacarandá, caroba & & & $\mathrm{x}$ & & 3 & 5118 \\
\hline & Tabebuia aurea (Silva Manso) Benth. \& Hook.f. ex S. Moore & $\begin{array}{l}\text { paratudo, ipê- } \\
\text { amarelo }\end{array}$ & $\mathrm{x}$ & $\mathrm{x}$ & $\mathrm{x}$ & $\mathrm{x}$ & 14 & 5119 \\
\hline & Tabebuia roseoalba (Ridl.) Sandwith & ipê-branco & $\mathrm{x}$ & & $\mathrm{x}$ & & 7 & 5120 \\
\hline \multirow{3}{*}{ Boraginaceae } & Cordia americana (L.) Gottschling \& J.S.Mill. & guajuvira & $\mathrm{x}$ & $\mathrm{x}$ & & & 4 & 5121 \\
\hline & Cordia sellowiana Cham. & chá-de-bugre & & & & & 1 & 5122 \\
\hline & Cordia trichotoma (Vell.) Arráb. ex Steud. & louro-pardo & $\mathrm{x}$ & & $\mathrm{x}$ & & 3 & 5123 \\
\hline \multirow{3}{*}{ Combretaceae } & Combretum leprosum Mart. & carne-de-vaca & & & & & 1 & 5124 \\
\hline & Terminalia argentea Mart. & capitão & & $\mathrm{x}$ & $\mathrm{x}$ & $\mathrm{x}$ & 12 & 5125 \\
\hline & Terminalia sp. & alazão & & & & & 1 & 5126 \\
\hline \multirow{2}{*}{ Euphorbiaceae } & Adelia membranifolia (Müll. Arg.) Chodat \& Hassl. & espinheiro & & & & & 1 & 5127 \\
\hline & Pleradenophora membranifolia (Müll. Arg.) Esser \& A. L. Melo & sarandi & & & & & 1 & 5128 \\
\hline \multirow{21}{*}{ Fabaceae } & Acosmium cardenasii H.S.Irwin \& Arroyo & falso-alecrim & $\mathrm{x}$ & & & & 3 & 5129 \\
\hline & Anadenanthera colubrina (Vell.) Brenan & angico & $\mathrm{x}$ & $\mathrm{x}$ & $\mathrm{x}$ & & 13 & 5130 \\
\hline & Bowdichia virgilioides Kunth & sucupira-preta & & $x$ & $\mathrm{x}$ & $\mathrm{x}$ & 13 & 5131 \\
\hline & Copaifera langsdorffii Desf. & copaíba & & $\mathrm{x}$ & $\mathrm{x}$ & $\mathrm{x}$ & 9 & 5132 \\
\hline & Dipteryx alata Vogel & baru, cumbaru & & $\mathrm{x}$ & $\mathrm{x}$ & $\mathrm{x}$ & 9 & 5133 \\
\hline & Diptychandra aurantiaca Tul. & carvão-vermelho & $\mathrm{x}$ & & $\mathrm{x}$ & $\mathrm{x}$ & 6 & 5134 \\
\hline & Enterolobium contortisiliquum (Vell.) Morong & marizeiro & & & & & 1 & 5135 \\
\hline & Geoffroea spinosa Jacq. & tamboril & $\mathrm{x}$ & $\mathrm{x}$ & & & 6 & 5136 \\
\hline & Guibourtia hymenaeifolia (Moric.) J. Léonard & jatobá-mirim & & & & & 1 & 5137 \\
\hline & Holocalyx balansae Micheli & alecrim & & $\mathrm{x}$ & & & 2 & 5138 \\
\hline & Hymenaea courbaril L. & jatobá & $\mathrm{x}$ & $\mathrm{x}$ & & & 4 & 5139 \\
\hline & Inga vera Willd. & ingá & $\mathrm{x}$ & $\mathrm{x}$ & & & 4 & 5140 \\
\hline & Leptolobium elegans Vogel & $\begin{array}{l}\text { perobinha-do- } \\
\text { campo }\end{array}$ & & $\mathrm{x}$ & $\mathrm{x}$ & & 4 & 5141 \\
\hline & Lonchocarpus cultratus (Vell.) A.M.G.Azevedo \& H.C. Lima & embira-de-sapo & $\mathrm{x}$ & & & & 4 & 5142 \\
\hline & Machaerium acutifolium Vogel & jacarandá-do-campo & $\mathrm{x}$ & & $\mathrm{x}$ & $\mathrm{x}$ & 9 & 5143 \\
\hline & Machaerium villosum Vogel & jacarandá-paulista & $\mathrm{x}$ & $\mathrm{x}$ & & & 3 & 5144 \\
\hline & Peltophorum dubium (Spreng.) Taub. & canafístula & & $\mathrm{x}$ & & & 2 & 5145 \\
\hline & Plathymenia reticulata Benth. & vinhático & & & $\mathrm{x}$ & $\mathrm{x}$ & 8 & 5146 \\
\hline & Platypodium elegans Vogel & $\begin{array}{l}\text { amendoim-do- } \\
\text { campo }\end{array}$ & $\mathrm{x}$ & $\mathrm{x}$ & $\mathrm{x}$ & $\mathrm{x}$ & 8 & 5147 \\
\hline & Sweetia fruticosa Spreng. & sucupira-amarela & $\mathrm{x}$ & & & & 2 & 5148 \\
\hline & Tachigali vulgaris L. G. Silva \& H. C. Lima & carvoeiro & & & $\mathrm{x}$ & $\mathrm{x}$ & 5 & 5149 \\
\hline
\end{tabular}


TABELA 2: Continuação...

TABLE 2: Continued...

\begin{tabular}{|c|c|c|c|c|c|c|c|c|}
\hline \multirow{2}{*}{ Família } & \multirow{2}{*}{ Espécie } & \multirow{2}{*}{ Nome popular } & \multicolumn{6}{|c|}{ Ocorrência } \\
\hline & & & FED & FES & $\mathrm{CD}$ & CSS & TA & Reg. \\
\hline Lecythidaceae & Cariniana legalis (Mart.) Kuntze & jequitibá-rosa & & $\mathrm{x}$ & & & 2 & 5150 \\
\hline Lythraceae & Lafoensia pacari A. St.-Hil. & pacarí & $\mathrm{x}$ & $\mathrm{x}$ & $\mathrm{x}$ & $\mathrm{x}$ & 11 & 5151 \\
\hline Malpighiaceae & Byrsonima coccolobifolia Kunth & murici-rosa & & & $\mathrm{x}$ & $\mathrm{x}$ & 10 & 5152 \\
\hline \multirow{5}{*}{ Malvaceae } & Bastardiopsis densiflora (Hook. \& Arn.) Hassl. & louro-branco & & & & & 1 & 5153 \\
\hline & Guazuma ulmifolia Lam. & $\begin{array}{l}\text { araticum-bravo, } \\
\text { cabeca-de-negro }\end{array}$ & $\mathrm{x}$ & $\mathrm{x}$ & $\mathrm{x}$ & & 10 & 5154 \\
\hline & Helicteres lhotzkyana (Schott \& Endl.) K. Schum. & saca-rolha & & & & & 1 & 5155 \\
\hline & Luehea paniculata Mart. \& Zucc. & açoita-cavalo & & $\mathrm{x}$ & $\mathrm{x}$ & & 4 & 5156 \\
\hline & Pseudobombax tomentosum (Mart. \& Zucc.) A. Robyns & imbiruçu & $\mathrm{x}$ & & $\mathrm{x}$ & $\mathrm{x}$ & 7 & 5157 \\
\hline \multirow{5}{*}{ Meliaceae } & Cedrela fissilis Vell. & cedro-rosa & $\mathrm{x}$ & & & & 3 & 5158 \\
\hline & Guarea sp. & chico-magro & & & & & 1 & 5159 \\
\hline & Trichilia catigua A. Juss. & catiguá-vermelho & $\mathrm{x}$ & $\mathrm{x}$ & & & 6 & 5160 \\
\hline & Trichilia pallida Sw. & catiguá & & $\mathrm{x}$ & & & 5 & 5161 \\
\hline & Trichilia silvatica C. DC. & catiguá-branco & & & & & 1 & 5162 \\
\hline \multirow{4}{*}{ Moraceae } & Ficus guaranitica Chodat & figueira-branca & $\mathrm{x}$ & $\mathrm{x}$ & & & 3 & 5163 \\
\hline & Ficus obtusifolia Kunth & figueira & & & & & 1 & 5164 \\
\hline & Maclura tinctoria (L.) D. Donex Steud. & amora-branca & $\mathrm{x}$ & $\mathrm{x}$ & & & 6 & 5165 \\
\hline & Sorocea sprucei (Baill.) J. F. Macbr. & figueira & & & & & 1 & 5166 \\
\hline \multirow{5}{*}{ Myrtaceae } & Campomanesia sp. & & & & & & 1 & 5167 \\
\hline & Eugenia florida DC. & guamirim & $\mathrm{x}$ & $\mathrm{x}$ & & & 5 & 5168 \\
\hline & Eugenia myrcianthes Nied. & uvaia & $\mathrm{x}$ & $\mathrm{x}$ & & & 3 & 5169 \\
\hline & Psidium sartorianum (O.Berg) Nied. & cambuí & $\mathrm{x}$ & & & & 2 & 5170 \\
\hline & Myrtaceae 1 & & & & & & 1 & 5171 \\
\hline \multirow{2}{*}{ Nyctaginaceae } & Guapira areolata (Heimerl) Lundell & maria-mole & $\mathrm{x}$ & & & & 2 & 5172 \\
\hline & Guapira hirsuta (Choisy) Lundell & carne-de-vaca & & & & & 1 & 5173 \\
\hline Oleaceae & Priogymnanthus hasslerianus (Chodat) P. S. Green & pau-vidro & $\mathrm{x}$ & & $\mathrm{x}$ & & 3 & 5174 \\
\hline Opiliaceae & Agonandra brasiliensis Miersex Benth. \& Hook. f. & tinge-cuia & & & $\mathrm{x}$ & $\mathrm{x}$ & 5 & 5175 \\
\hline Primulaceae & Myrsine umbellata Mart. & capororoca & $\mathrm{x}$ & $\mathrm{x}$ & $\mathrm{x}$ & $\mathrm{x}$ & 7 & 5176 \\
\hline Ramnaceae & Rhamnidium elaeocarpum Reissek & cabriteiro & $\mathrm{x}$ & $\mathrm{x}$ & $\mathrm{x}$ & & 10 & 5177 \\
\hline \multirow{5}{*}{ Rubiaceae } & Calycophyllum multiflorum Griseb. & castelo & $\mathrm{x}$ & & & & 3 & 5178 \\
\hline & Cordiera sessilis (Vell.) Kuntze & marmelo & $\mathrm{x}$ & & $\mathrm{x}$ & $\mathrm{x}$ & 6 & 5179 \\
\hline & Coussarea hydrangeaefolia (Benth.) Müll. Arg. & quina & & & $\mathrm{x}$ & & 3 & 5180 \\
\hline & Genipa americana $\mathrm{L}$. & jenipapo & & & & & 1 & 5181 \\
\hline & Guettarda viburnoides Cham. \& Schltdl. & veludo & $\mathrm{x}$ & $\mathrm{x}$ & $\mathrm{x}$ & & 8 & 5182 \\
\hline \multirow{2}{*}{ Rutaceae } & Balfourodendron riedelianum (Engl.) Engl. & pau-marfim & & & & & 1 & 5183 \\
\hline & Zanthoxylum sp. & mamica-de-porca & & & & & 1 & 5184 \\
\hline \multirow{3}{*}{ Salicaceae } & Casearia gossypiosperma Briq. & pau-de-espeto & $\mathrm{x}$ & $\mathrm{x}$ & & $\mathrm{x}$ & 7 & 5185 \\
\hline & Casearia rupestris Eichler & pururuca & $\mathrm{x}$ & & $\mathrm{x}$ & & 6 & 5186 \\
\hline & Casearia sylvestris Sw. & guaçatonga & $\mathrm{x}$ & $\mathrm{x}$ & $\mathrm{x}$ & $\mathrm{x}$ & 13 & 5187 \\
\hline \multirow{6}{*}{ Sapindaceae } & Averrhoidium paraguaiense Radlk. & maria-preta & & & & & 1 & 5188 \\
\hline & Cupania vernalis Cambess. & camboatã & $\mathrm{x}$ & $\mathrm{x}$ & $\mathrm{x}$ & & 6 & 5189 \\
\hline & Dilodendron bipinnatum Radlk. & maria-mole & $\mathrm{x}$ & $\mathrm{x}$ & $\mathrm{x}$ & & 12 & 5190 \\
\hline & Magonia pubescens A. St.-Hil. & timbó & $\mathrm{x}$ & & $\mathrm{x}$ & $\mathrm{x}$ & 9 & 5191 \\
\hline & Matayba elaeagnoides Radlk. & pau-de-pombo & & $\mathrm{x}$ & $\mathrm{x}$ & & 6 & 5192 \\
\hline & Talisia esculenta (Cambess.) Radlk. & pitomba & $\mathrm{x}$ & $\mathrm{x}$ & & & 3 & 5193 \\
\hline Sapotaceae & Chrysophyllum gonocarpum (Mart. \& Eichler ex Miq.) Engl. & aguaí & $\mathrm{x}$ & & & & 2 & 5194 \\
\hline \multirow{2}{*}{ Urticaceae } & Boehmeria caudata $\mathrm{Sw}$. & urtiga & & & & & 1 & 5195 \\
\hline & Cecropia pachystachya Trécul & embaúba & $\mathrm{x}$ & $\mathrm{x}$ & $\mathrm{x}$ & $\mathrm{x}$ & 8 & 5196 \\
\hline \multirow{4}{*}{ Vochysiaceae } & Callisthene fasciculata Mart. & jacaré, carvoeiro & $\mathrm{x}$ & & $\mathrm{x}$ & & 7 & 5197 \\
\hline & Qualea cordata (Mart.) Spreng. & pau-terra & & & & & 1 & 5198 \\
\hline & Qualea grandiflora Mart. & pau-terra-grande & $\mathrm{x}$ & & $\mathrm{x}$ & $\mathrm{x}$ & 13 & 5199 \\
\hline & Qualea parviflora Mart. & pau-terra-roxo & & $\mathrm{x}$ & $\mathrm{x}$ & $\mathrm{x}$ & 13 & 5200 \\
\hline
\end{tabular}




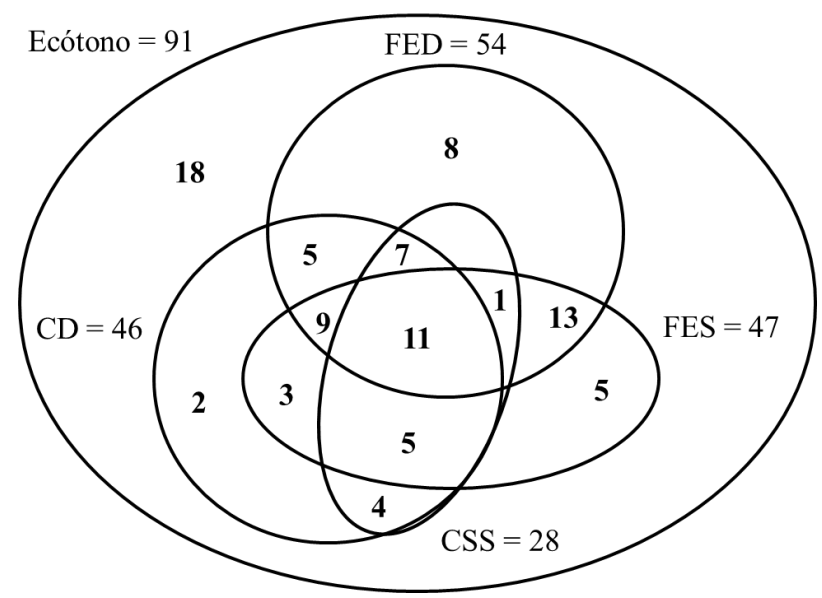

FIGURA 2: Distribuição do número de espécies de um levantamento florístico em ecótono no Planalto da Bodoquena por fitofisionomia de ocorrência, a partir dos registros em outros 25 estudos no Centro-Oeste e Sudeste do Brasil. Em que: FED = Floresta Estacional Decidual; FES = Floresta Estacional Semidecidual $; \mathrm{CD}=$ cerradão; $\mathrm{CSS}=$ cerrado sensu stricto .

FIGURE 2: Distribution of number of a floristic survey of the species of ecotone in the Bodoquena Plateau by vegetation type of occurrence, according to the records of 25 other studies in the Midwest and Southeast regions of Brazil.. Wherein: FED = Deciduous Forest; FES = Semideciduous Seasonal Forest; $\mathrm{CD}=$ cerradão; $\mathrm{CSS}=$ cerrado sensu stricto.

e quatro compartilhadas entre CD e CSS.

Várias espécies encontradas neste levantamento são consideradas típicas de cerradão (SOLÓRZANO et al., 2012), como Qualea grandiflora, Qualea parviflora e Bowdichia virgilioides que estiveram presentes em todas as fisionomias de cerrado incluídas, além daquelas de menor ocorrência, que é o caso de Tachigali vulgaris, Dipteryx alata, Astronium fraxinifolium, Machaerium acutifolium, Platypodium elegans, Coussarea hydrangeaefolia, Guettarda viburnoides, Plathymenia reticulata e Terminalia argentea. A deciduidade constatada para estas espécies está relacionada à estacionalidade do clima local, como estratégia das espécies para adaptar-se à escassez de água no período de baixa pluviosidade, sendo o cerradão composto por espécies xeromórficas típicas do Cerrado, mas também por espécies florestais, e este conjunto lhe confere características florísticas e estruturais próprias (RIBEIRO; WALTER, 2008).

Cinco espécies são de compartilhamento exclusivo entre FED e cerradão, dentre as quais estão Callisthene fasciculata e Tabebuia roseoalba, ocorrentes em sete áreas cada, ambas muito representativas na área de ecótono amostrada. No total, 32 espécies foram comuns entre cerradão e FED, o que corresponde a $59,3 \%$ das encontradas para floresta decidual (54), e 35,2\% do total de registros no ecótono. De forma geral, cerca de $20 \%$ das espécies que ocorrem nas FED do Brasil Central ocorrem também em cerradão mesotrófico e a similaridade pedológica é considerada o principal fator da similaridade florística (OLIVEIRA-FILHO; RATTER, 1995; 2002; HENRIQUES, 2005). Quanto à umidade, tanto o cerradão como a FED ocorrem nos interflúvios, em terrenos bem drenados. Sugere-se, inclusive, que ambos pertençam ao mesmo tipo de unidade florístico-fisionômica, com as florestas estacionais sobre solos mais férteis, muitas vezes associadas a afloramentos de rochas básicas (HENRIQUES, 2005), nos quais há maiores níveis de cálcio e fósforo (RATTER, 1992). Ribeiro e Walter (2008) afirmaram que, para distinguir a floresta decídua, ou "mata seca", de cerradão, devem ser considerados parâmetros estruturais e florísticos, mas esta diferenciação torna-se problemática em ecótonos.

Sobre as florestas deciduais no Brasil, Soares Filho (2012) concluiu em seu estudo que estas possuem diversidade média a alta com padrão fitogeográfico heterogêneo. Embora se conheçam os padrões florísticos para FED e FES (OLIVEIRA-FILHO; JARENKOW; RODAL, 2006), ainda são desconhecidas as divergências florísticas entre estas (KILCA; SCHIAVINI; MONTEIRO, 2014).

No dendrograma gerado para as 26 áreas incluídas na análise, distinguiu-se um agrupamento das 


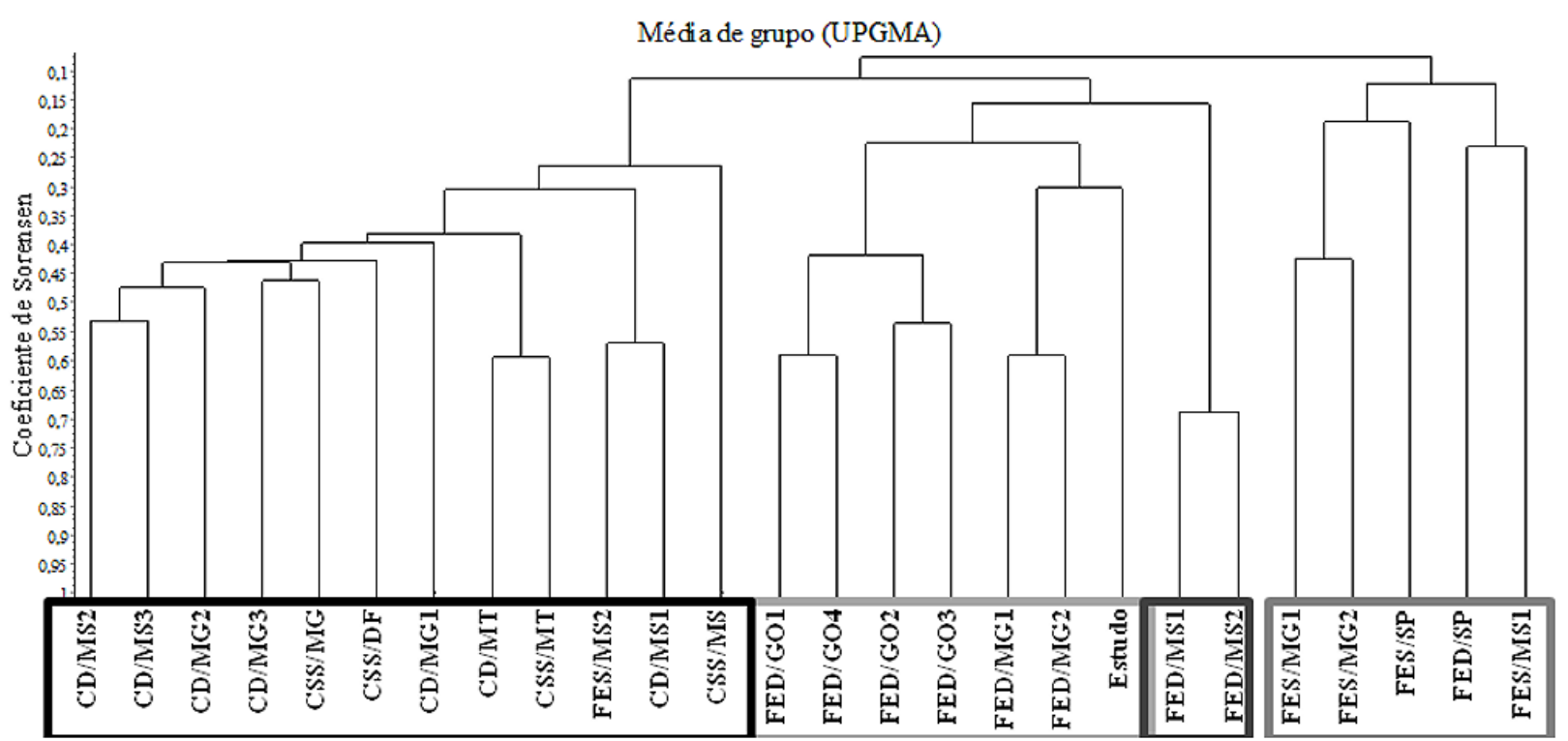

Em que: Ecótono no Planalto da Bodoquena - Bonito, MS = Estudo; áreas de Floresta Estacional Decidual = FED; Floresta Estacional Semidecidual $=\mathrm{FES}$; cerradão $=\mathrm{CD}$; cerrado sensu stricto $=\mathrm{CSS}$; Estados do Sudeste: $\mathrm{MG}$, SP; Estados do Centro-Oeste: GO, MS, MT; Distrito Federal =DF.

FIGURA 3: Similaridade florística de 26 levantamentos no Sudeste e Centro-Oeste do Brasil. FIGURE 3: Floristic similarity of 26 surveys in the Southeast and Midwest of Brazil.

florestas deciduais, porém, com baixa similaridade e grande heterogeneidade florística, sendo que a área de estudo apresentou maior similaridade, de apenas 30\%, com FED de Minas Gerais (Figura 3). Corroborando este estudo, Medeiros, Walter e Oliveira (2014) também encontraram, no fragmento que estudaram, uma florística particular e baixa similaridade entre áreas de FED.

A Floresta Estacional Decidual é característica dos interflúvios e apresenta deciduidade da comunidade arbustivo-arbórea acima de $50 \%$ dos indivíduos ao final do período de estiagem (IBGE, 2012), sendo encontrada nas encostas do Planalto da Bodoquena, com predomínio de ecótipos savanícolas e florestais mesofanerofíticos, constituídos por gêneros afro-amazônicos e andino-argentinos (PRADO; GIBBS, 1993; IBGE, 2004). O estudo de Ratter e Dargie (1992), com 26 áreas de cerrado, mostrou que a vegetação possui baixa similaridade, sendo extremamente heterogênea, o que reforça o atual resultado. Neste sentido, atesta-se a elevada diversidade beta para as áreas analisadas.

Felfili e Silva-Júnior (2005), ao encontrarem maior similaridade florística entre áreas mais distantes, observaram que os gradientes de solo e relevo podem exercer maior influência nos padrões de diversidade beta do que as variações latitudinais e longitudinais dentro do bioma Cerrado, corroborando os resultados encontrados neste estudo. Portanto, a distância geográfica entre a área de estudo e as demais áreas não foi o fator determinante da similaridade, assim, outros fatores devem ser considerados. $\mathrm{O}$ vale do rio Araguari (FED/MG1, FED/MG2) e o morro amostrado possuem semelhanças ambientais, como as condições climáticas, ocorrência sobre afloramentos rochosos, Neossolo Litólico raso e área de cerradão nas proximidades, sendo possível que haja também a influência de um tipo florístico sobre o outro.

O que poderia diferenciar e caracterizar as fitofisionomias são as espécies indicadoras. Ratter (1992) cita, como principais espécies indicadoras de FED, Myracrodruon urundeuva, Astronium fraxinifolium, Aspidosperma subincanum, Handroanthus impetiginosus e Cedrela fissilis, mas aqui apenas a última foi exclusiva para tal fisionomia, e as demais se apresentaram como de ampla distribuição. Ratter et al. (1988) trazem como indicadoras de cerradão mesotrófico: Acrocomia aculeata, Callisthene fasciculata, Dipteryx alata, Guettarda viburnoides, Jacaranda cuspidifolia, Magonia pubescens, Pseudobombax tomentosum e Terminalia argentea. Destas, apenas Jacaranda cuspidifolia foi exclusiva dos cerrados, e as demais de ampla distribuição.

Em mapeamento das florestas estacionais do Domínio Cerrado em Minas Gerais, Dutra, Carvalho e 
Oliveira Filho (2007), através de análise de espécies indicadoras, encontraram cinco espécies arbóreas para este domínio, sendo elas: Myracrodruon urundeuva, Dilodendron bipinnatum, Aspidosperma subincanum, Handroanthus impetiginosus e Tabebuia roseoalba. As quatro primeiras tiveram ampla distribuição neste estudo, sendo que a última ocorreu em FED e cerradão.

Todavia, não há consenso entre os autores sobre quais são e se é possível determinar espécies indicadoras para estas formações. $\mathrm{Na}$ bacia do rio Palma, Tocantins, em diferentes fitofisionomias e em ecótonos de contato Savana/Floresta, Dias et al. (2011) encontraram espécies caracterizadas como indicadoras, preferenciais e de ampla distribuição para as florestas estacionais daquela região, na qual 14 coincidiram com a vegetação arbórea do Planalto da Bodoquena. Em uma lista de 84 espécies sugeridas como indicadoras de FED, resultante do estudo de Almeida e Machado (2007), 19 estão contidas no presente levantamento, sendo que destas, 11 são descritas como componentes da região centro-leste, três são da região sul e cinco são encontradas em Corumbá - MS (região sudoeste). Em se tratando de floresta decidual, há maior correlação florística da área estudada com as espécies descritas nos estudos de Minas Gerais, Goiás e São Paulo, do que com os quatro levantamentos de Mato Grosso do Sul. Deve-se considerar a escassez de estudos e a localização geográfica dos pontos amostrados em MS - somente Corumbá - como fatores limitantes ao conhecimento mais abrangente da flora destas comunidades.

A oeste, na sub-região de Porto Murtinho, área adjacente a Serra da Bodoquena, foram mapeados ecótonos de floresta decídua e chaco (SILVA et al., 2000; BRASIL, 2007), onde, em estudo técnico, BaptistaMaria e Maria (2009) amostraram a flora constatando a presença de espécimes de ambas as fisionomias. Pott e Pott (2009) classificaram como sendo originárias de floresta estacional e chaco Adelia membranifolia e Calycophyllum multiflorum, além de Tabebuia aurea, que é característica de cerrado, mas relacionada floristicamente com o chaco (POTT; POTT; DAMASCENO JÚNIOR, 2009).

Em trabalho sobre a dinâmica e fitogeografia do Pantanal, Pott e Pott (2009) argumentaram que muitas das árvores caducifólias se assemelham às do "Bosque Seco Chiquitano" da Bolívia, que possui espécies associadas ao cerradão mesotrófico, colocando como exemplos: Acrocomia aculeata, Astronium fraxinifolium, Callisthene fasciculata, Dipteryx alata, Luehea paniculata e Magonia pubescens, comuns a este levantamento.

Nos biomas sul-americanos a maioria das espécies lenhosas tem distribuição em duas ou mais províncias biogeográficas, como o caso de Anadenanthera colubrina que é comum no Pantanal, mas frequentemente encontrada nas florestas estacionais da América do Sul (PRADO; GIBBS, 1993; POTT; POTT; DAMASCENO JÚNIOR, 2009). Na planície pantaneira, há ocorrências comuns à Mata Atlântica e a este estudo, como Astronium fraxinifolium, Casearia sylvestris, Cecropia pachystachya, Cedrela fissilis, Enterolobium contortisiliquum, Eugenia florida, Guazuma ulmifolia, Hymenaea courbaril, Maclura tinctoria, Handroanthus impetiginosus, Handroanthus ochraceus e Tapirira guianenses, presentes desde florestas ripárias até florestas deciduais (POTT; POTT; DAMASCENO JÚNIOR, 2009).

No Pantanal, Damasceno-Junior et al. (2009) listaram as espécies registradas em florestas deciduais, das quais 23 coincidem com este levantamento, com destaque para Myracrodruon urundeuva, Astronium fraxinifolium, Attalea phalerata, ipês (Handroanthus spp. e Tabebuia spp.), Combretum leprosum, Guazuma ulmifolia, Maclura tinctoria e Dilodendron bipinnatum, de ampla distribuição naquele ecossistema. Outras espécies aqui registradas e de ampla dispersão no Pantanal são Agonandra brasiliensis, Luehea paniculata, Magonia pubescens e Terminalia argentea, que são consideradas espécies do Cerrado, mas que comumente ocorrem em florestas estacionais.

Quanto à origem dos táxons encontrados, tem-se que a grande região florística amazônica provavelmente seja o berço de diversas famílias endêmicas da Zona Neotropical, dando início a uma dispersão florística de amplitude pantropical, como é o caso de Sapotaceae, Meliaceae e Malvaceae, e de famílias com origem filogenética comprovada por fósseis encontrados em depósitos do Cretáceo e Terciário, dentre as quais está Fabaceae. Lecythidaceae, aqui representada por Cariniana legalis, é outra típica família de origem afro-amazônica (IBGE, 2012).

Goodland e Ferri (1979) declararam que Vochysiaceae é uma pequena família neotropical e provavelmente seja a mais característica do cerrado, composta por seis gêneros que também são exemplos da expansão da flora afro-amazônica para o interior da vegetação do cerrado no Brasil Central. Qualea ocorre frequentemente fora do espaço amazônico, sendo predominantemente submontana e distribuída 
até o extremo sul da Savana (Cerrado). Callisthene, que possui maior número de espécies na fisionomia savânica, mas também ocorre nas florestas estacionais, é encontrado atualmente na região amazônica em áreas litólicas e disjunções do Cerrado inseridas na floresta (IBGE, 2012).

Fabaceae e Rubiaceae estão dentre as quatro maiores famílias terrestres da flora mundial, com ampla ocorrência no Cerrado. Fabaceae foi a mais representativa em número de espécies, e dentre os gêneros mais expressivos desta família no bioma foram descritas Bowdichia, seguida por Sweetia, Machaerium, Hymenaea, Plathymenia, Tachigali e Copaifera. Já as Rubiaceae estão aqui representadas por Calycophyllum, Cordiera, Coussarea, Genipa e Guettarda. Semelhantemente, Malphighiceae, com o gênero Byrsonima, é de ampla distribuição neste bioma (GOODLAND; FERRI, 1979). Meliaceae, Moraceae e Myrtaceae apresentaram ocorrência apenas nas florestas estacionais, demonstrando a ligação da área estudada com a floresta atlântica (LEITÃO-FILHO, 1987).

Afirma-se que mais da metade da flora savânica do Brasil central tenha se originado de outros tipos vegetacionais, os quais influenciam o Cerrado pela proximidade nas bordas, e chegam às áreas centrais através das matas ciliares que cortam os biomas seguindo o curso dos rios (RIZZINI, 1997; FELFILI; SOUSA-SILVA; SCARIOT, 2005). A expansão da flora amazônica para o sul de sua localização atual teria ocorrido em tempo geológico recente, no período glacial andino do Quaternário, há, aproximadamente, 15.000 anos, e considera-se que a flora hoje presente no domínio do Cerrado seja quase inteiramente composta por estas famílias e gêneros, com adaptações fenotípicas às novas condições ambientais (IBGE, 2012).

\section{CONCLUSÕES}

A elevada riqueza e a característica ecotonal do fragmento estudado decorrem da sobreposição das floras dos domínios Cerrado e Mata Atlântica, com influência do chaco úmido ocorrente no Pantanal. Embora a maioria de suas espécies tenha sido descrita nas florestas estacionais, o conjunto florístico amostrado contempla uma variedade comumente encontrada em cerradão e outras exclusivas deste levantamento, demonstrando elevada complexidade florística.

$\mathrm{O}$ agrupamento do ecótono com as demais listas florísticas resultou em baixa similaridade, determinada por valores iguais a menores que $30 \%$ do coeficiente de Sorensen. A diversidade beta das áreas estudadas foi elevada.

As 33 espécies que apresentaram ampla distribuição são indicadas para serem utilizadas em programas de restauração ecológica em áreas de florestas estacionais, cerrado sensu stricto e cerradão, além da transição cerrado-floresta, pelo seu potencial de adaptação a condições físicas e ambientais diversas. Ressalta-se a importância da realização de estudos na região, com vistas à proteção e conservação de sua biodiversidade ímpar, sobretudo considerando o contexto de pressão do setor econômico sobre o ambiental.

\section{REFERÊNCIAS}

ALMEIDA, H. S.; MACHADO, E. L. M. Espécies indicadoras de componente arbóreo em comunidades de floresta estacional decídua. Nota científica. Revista Brasileira de Biociências, Porto Alegre, v. 5, supl 1, p. 654-656, jul. 2007.

ANGIOSPERM PHYLOGENY GROUP III. An update of the Angiosperm Phylogeny Group classification for the orders and families of flowering plants: APG III. Botanical Journal of Linnean Society, London, v. 161, p. 105-121, 2009.

ARAÚJO, H. J. T. et al. Geologia. In: PROJETO RADAMBRASIL. Folha SF-21 Campo Grande. Levantamento de Recursos Naturais, 28. Rio de Janeiro: MME, 1982, p. 9-124.

ARRUDA, L.; DANIEL, O. Florística e diversidade em um fragmento de Floresta Estacional Semidecidual Aluvial em Dourados - MS. Floresta, Curitiba, v. 37, n. 2, p. 189-199, 2007.

ASSUNÇÃO, S. L.; FELFILI, J. M. Fitossociologia de um fragmento de cerrado sensu stricto na APA do Paranoá, DF, Brasil. Acta Botanica Brasilica, Belo Horizonte, v. 18, p. 903-909, 2004.

BAPTISTA-MARIA, V. R.; MARIA, F. S. Espécies da flora encontrada no Fecho dos Morros, Porto Murtinho - MS. Inventário florístico do Corredor de Biodiversidade Miranda - Serra da Bodoquena, 
anexo 1. Bonito: Neotrópica, 2009. 44 p.

BAPTISTA-MARIA, V. R. et al. Composição florística de florestas estacionais ribeirinhas no estado de Mato Grosso do Sul, Brasil. Acta Botanica Brasilica, Belo Horizonte, v. 23, p. 535-548, 2009.

BATTILANI, J. L.; SCREMIN-DIAS, E. S.; SOUZA, A. L. T. Fitossociologia de um trecho da mata ciliar do rio da Prata, Jardim, MS, Brasil. Acta Botanica Brasilica, Belo Horizonte, v. 19, p. 597-608, 2005.

BRASIL. Ministério do Meio Ambiente. Biodiversidade Brasileira. Avaliação e identificação de áreas e ações prioritárias para conservação, utilização sustentável e repartição dos benefícios da biodiversidade nos biomas brasileiros. Brasília: MMA/SBF, 2002. 404 p.

BRASIL. Ministério do Meio Ambiente. Biodiversidade do Cerrado e Pantanal: áreas e ações prioritárias para conservação. Brasília: MMA, 2007. 540 p. (Série Biodiversidade, 17).

BUENO, M. L. et al. Influence of edaphic factors on the floristic composition of an area of cerradão in the Brazilian central-west. Acta Botanica Brasilica, Belo Horizonte, v. 27, p. 445-455, 2013.

CAMILOTTI, D. C.; PAGOTTO, T. C. S.; ARAUJO, A. C. Análise da vegetação arbórea de um remanescente de Cerradão em Bandeirantes, Mato Grosso do Sul, Brasil. Iheringia, Série Botânica, Porto Alegre, v. 66, n. 1, p. 31-46, jul. 2011.

CAMPOS, E. P. et al. Composição florística de um trecho de Cerradão e Cerrado Sensu stricto e sua relação com o solo na floresta nacional. (Flona) de Paraopeba, MG, Brasil. Revista Árvore, Viçosa, MG, v. 30, n. 3, p. 471-479, 2006.

CARVALHO, F. A.; FELFILI, J. M. Variações temporais na comunidade arbórea de uma floresta decidual sobre afloramentos calcários no Brasil Central: composição, estrutura e diversidade florística. Acta Botanica Brasilica, Belo Horizonte, v. 25, p. 203-214, 2011.

DAMASCENO-JUNIOR, G. A. et al. Florestas estacionais no Pantanal, considerações florísticas e subsídios para conservação. In: SIMPÓSIO DE GEOTECNOLOGIAS NO PANTANAL, 2., 2009. Anais... Corumbá: Embrapa Informática Agropecuária; INPE, 2009. p. 784-795.

DIAS, J. A região cárstica de Bonito, MS: uma proposta de zoneamento geoecológico a partir de unidades de paisagem. Ensaios e Ciência, Campo Grande, v. 4, n. 1, p. 9-43, 2000.

DIAS, R. R. et al. Delimitação, estrutura e diversidade dos ambientes e fitofisionomias florestais na bacia do rio Palma, estado do Tocantins, Amazônia Legal. In: SIMPÓSIO BRASILEIRO DE SENSORIAMENTO REMOTO - SBSR, 15., 2011. Anais... Curitiba: INPE, 2011. p. 2075-2082.

DURIGAN, G.; RATTER, J. A. Successional changes in cerradão and cerrado/ forest ecotonal vegetation in western São Paulo State, Brazil, 1962-2000. Edinburgh Journal of Botany, Cambridge, v. 63, p. 119-130, 2006.

DUTRA, C. D.; CARVALHO, L. M. T.; OLIVEIRA FILHO, A. T. Modelagem espacial de florestas estacionais do Domínio Cerrado no Estado de Minas Gerais utilizando envelope climático. In: BRAZILIAN SIMPOSIUM ON GEOINFORMATICS, 9., 2007. Anais... Campos do Jordão: INPE, 2007. p. 257-262.

FELFILI, J. M.; SILVA-JÚNIOR, M. C. Diversidade alfa e beta no cerrado sensu stricto, Distrito Ferderal, Goiás, Minas Gerais e Bahia. In: SCARIOT, A.; SOUSA-SILVA, J. C.; FELFILI, J. M. (Org.). Cerrado: ecologia, biodiversidade e conservação. Brasília: MMA, 2005. p. 141-154.

FELFILI, J. M.; SOUSA-SILVA, J. C.; SCARIOT, A. Biodiversidade, ecologia e conservação do Cerrado: avanços no conhecimento. In: SCARIOT, A.; SOUSA-SILVA, J. C.; FELFILI, J. M. (Org.). Cerrado: ecologia, biodiversidade e conservação. Brasília: MMA, 2005. p. 25-44.

GOODLAND, R. J. A.; FERRI, M. G. Ecologia do cerrado. Belo Horizonte: Itatiaia, 1979. 193 p.

HENRIQUES, R. P. B. Influência da história, solo e fogo na distribuição e dinâmica das fitofisionomias no bioma do Cerrado. In: SCARIOT, A.; SOUSA-SILVA, J. C.; FELFILI, J. M. (Org.). Cerrado: ecologia, biodiversidade e conservação. Brasília: MMA, 2005. p. 73-92.

IBGE. Manual técnico da vegetação brasileira. Rio de Janeiro: IBGE, 2012. 271 p.

IBGE. Mapa de Biomas do Brasil. Rio de Janeiro: IBGE, 2004. Disponível em: <http://mapas.ibge.gov. br/tematicos $>$. Acesso em: jan. 2014.

IVANAUSKAS, N. M.; RODRIGUES, R. R.; NAVE, A. G. Fitossociologia de um trecho de Floresta Estacional Semidecidual em Itatinga, São Paulo, Brasil. Scientia Forestalis, Piracicaba, n. 56, p. 83-99, dez. 1999.

IVANAUSKAS, N. M.; RODRIGUES, R. R. Florística e fitossociologia de remanescentes de floresta 
estacional decidual em Piracicaba, São Paulo, Brasil. Revista Brasileira de Botânica, São Paulo, v. 23, n. 3, p. 291-304, set. 2000.

JARDIM BOTÂNICO DO RIO DE JANEIRO. Lista de Espécies da Flora do Brasil. [2014]. Disponível em: $<$ http://floradobrasil.jbrj.gov.br/>. Acessado em: até dez. 2014.

KILCA, R. V.; SCHIAVINI, I.; MONTEIRO, G. A. Padrões florísticos em dois tipos de florestas estacionais no cerrado. Bioscience Journal, Uberlandia, v. 30, n. 3, p. 903-913, 2014.

LEHN, C. R.; ALVES, F. M.; DAMASCENO JUNIOR, G. A. Florística e fitossociologia de uma área de cerrado sensu stricto na região da borda oeste do Pantanal, Corumbá, MS, Brasil. Pesquisas, Botânica, São Leopoldo, n. 59, p. 129-142, 2008.

LEITÃO-FILHO, H. F. Considerações sobre a florística de florestas tropicais e sub-tropicais do Brasil. IPEF, Piracicaba, n. 35, p. 41-46, abr. 1987.

LIMA, M. S.; DAMASCENO-JÚNIOR, G. A.; TANAKA, M. O. Aspectos estruturais da comunidade arbórea em remanescentes de floresta estacional decidual, em Corumbá, MS, Brasil. Revista Brasileira de Botânica, São Paulo, v. 33, n. 3, p.437-453, jul./set. 2010.

MARANGON, L. C. et al. Estrutura fitossociológica e classificação sucessional do componente arbóreo de um fragmento de Floresta Estacional Semidecidual, no município de Viçosa, Minas Gerais. Cerne, Lavras, v. 13, n. 2, p. 208-221, abr./jun. 2007.

MARIMON JUNIOR, B. H.; HARIDASAN, M. Comparação da vegetação arbórea e características edáficas de um cerradão e um cerrado sensu stricto em áreas adjacentes sobre solo distrófico no leste de Mato Grosso, Brasil. Acta Botanica Brasilica, Belo Horizonte, v. 19, p. 913-926, 2005.

MARTINS, S. V. et al. Distribuição de espécies arbóreas em um gradiente topográfico de Floresta Estacional Semidecidual em Viçosa, MG. Scientia Forestalis, Piracicaba, n. 64, p. 172-181, dez. 2003.

MEDEIROS, M. B.; WALTER, B. M. T.; OLIVEIRA, W. L. Floristic and structural comparisons between woody communities of two seasonal forest fragments in the Tocantins river basin and other remnants of this forest physiognomy in Brazil. Rodriguésia, Rio de Janeiro, v. 65, p. 21-33, 2014.

NASCIMENTO, A. R. T.; FELFILI, F. M.; MEIRELLES, E. M. Florística e estrutura de um remanescente de Floresta Estacional Decidual de encosta, Monte Alegre, GO, Brasil. Acta Botanica Brasilica, Belo Horizonte, v. 18, p. 659-669, 2004.

OAKLEY, L. J.; PRADO, D. E. El dominio de los Bosques Secos Estacionales Neotropicales y la presencia del Arco Pleistocénico en la República del Paraguay. Rojasiana, Asunción, v. 10, p. 55-75, 2011.

OLIVEIRA-FILHO, A. T.; JARENKOW, J. A.; RODAL, M. J. N. Floristic relationships of seasonally dry forests of eastern South America based on tree species distribution patterns. In: PENNINGTON, R. T.; LEWIS, G. P.; RATTER, J. A. (Org.). Neotropical savannas and dry forests: plant diversity, biogeography and conservation. Boca Raton: CRC Press, 2006. p. 151-184.

OLIVEIRA-FILHO, A. T.; RATTER, J. A. A study of the origin of central Brazilian forests by the analysis of plant species distribution patterns. Edinburgh Journal of Botany, Cambridge, v. 52, p. 141-194, 1995. OLIVEIRA-FILHO, A. T.; RATTER, J. A. Padrões florísticos das matas ciliares da região dos cerrados e a evolução das paisagens do Brasil Central durante o Quaternário tardio. In: RODRIGUES, R. R.; LEITÃOFILHO, H. F. (Eds.). Matas Ciliares: bases multidisciplinares para estudo, conservação e restauração. São Paulo: EDUSP, 2000. p. 73-89.

OLIVEIRA-FILHO, A. T.; RATTER, J. A. Vegetation physiongnomies and woody flora of the cerrado biome. In: OLIVEIRA, P. S.; MARQUIS, R. J. (Eds.). The cerrados of Brazil: ecology an natural history of a Neotropical Savanna. New York: Columbia University Press, 2002. p. 91-120.

PENNINGTON, R. T., PRADO, D. E.; PENDRY, C. A. Neotropical seasonally dry forests and quaternary vegetation changes. Journal of Biogeography, Hoboken, v. 27, p. 261-273, 2000.

PINHEIRO, M. H. O.; MONTEIRO, R. Contribution of forest species to the floristic composition of a forested savanna in southeastern Brazil. Brazilian Archives of Biology and Technology, Curitiba, v. 49, p. 763-774, 2006.

POTT, A.; POTT, V. J. Vegetação do Pantanal: fitogeografia e dinâmica. In: SIMPÓSIO DE GEOTECNOLOGIAS NO PANTANAL, 2., 2009.. Anais... Corumbá: Embrapa Informática Agropecuária; INPE, 2009. p. 1065-1076.

POTT, A.; POTT, V. J.; DAMASCENO JÚNIOR, G. A. Fitogeografia do Pantanal. In: CLAE, 3.; CEB, 9., 
2009. Anais... São Lourenço: [s. n.], 2009.

PRADO, D. E.; GIBBS, P. Patterns of species distributions in the Dry Seasonal Forests of South America. Missouri Botanical Garden, St. Louis, v. 80, n. 4, p. 902-927, 1993.

RAMOS, W. M.; SARTORI, A. L. B. Floristic analysis and dispersal syndromes of woody species of the Serra de Maracaju, Mato Grosso do Sul, Brasil. Brazilian Journal of Biology, São Carlos, v. 73, n. 1, p. 67-78, 2013.

RATTER, J. A. Transitions between cerrado and forest vegetation in Brazil. In: FURLEY, P. A.; PROCTOR, J.; RATTER, J. A. (Eds). Nature and dynamics of forest savanna boundaries. London: Chapman \& Hall, 1992. p. 51-76.

RATTER, J. A. et al. Notes on woody vegetation types in the Pantanal and around Corumbá. Notes Royal Botanic Garden Edinburgh. Edinburgh, v. 45, p. 503-525, 1988.

RATTER, J. A.; DARGIE, T. C. D. An analysis of the floristic composition of 26 cerrado areas in Brazil. Edinburgh Journal of Botany, Edinburgh, v. 49, p. 235-250, 1992.

RIBEIRO, J. F.; WALTER, B. M. T. As Principais Fitofisionomias do Bioma Cerrado. In: SANO, S. M.; ALMEIDA, S. P.; RIBEIRO, J. F. (Eds.). Cerrado: ecologia e flora. Brasília: Embrapa Cerrados; Embrapa Informação Tecnológica, 2008. p. 151-212.

RIZZINI, C. T. Tratado de fitogeografia do Brasil: aspectos ecológicos, sociológicos e florísticos, 2. ed. Rio de Janeiro: Ambito Cultural, 1997. 747 p.

RODRIGUES, R. F.; ARAÚJO, G. M. Estrutura da vegetação e características edáficas de um cerradão em solo distrófico e em solo mesotrófico no Triângulo Mineiro. Bioscience Journal, Uberlandia, v. 29, n. 6 , p. 2013-2029, 2013.

SALIS, S. M. et al. Changes in the structure due to strong winds in forest areas in the Pantanal, Brazil. Cerne, Lavras, v. 18, n. 3, p. 387-395, jul./set. 2012.

SALIS, S. M. et al. Distribuição e abundância de espécies arbóreas em cerradões no Pantanal, Estado do Mato Grosso do Sul, Brasil. Revista Brasileira de Botânica, São Paulo, v. 29, n. 3, p. 339-352, 2006.

SALLUN FILHO, W. et al. Deposição de tufas quaternárias no Estado de Mato Grosso do Sul: proposta de definição da formação Serra da Bodoquena. Revista do Instituto de Geociências, São Paulo, v. 9, n. 3, p. 47-60, out. 2009.

SALLUN FILHO, W.; KARMANN, I. Geomorphological map of the Serra da Bodoquena karst, Westcentral Brazil. Journal of Maps, Abingdon, p. 282-295, 2007.

SANTOS, H. G. et al. Sistema brasileiro de classificação de solos. 2. ed. Rio de Janeiro: Embrapa Solos, 2006. $306 \mathrm{p}$.

SAPORETTI JUNIOR, A. W.; MEIRA NETO, J. A. A.; ALMADO, R. P. Fitossociologia de cerrado sensu stricto no município de Abaeté - MG. Revista Árvore, Viçosa, mg, v. 27, n. 3, p. 413-419, 2003.

SCARIOT, A.; SEVILHA, A. C. Biodiversidade, estrutura e conservação de florestas estacionais deciduais no Cerrado. In: SCARIOT, A.; SOUSA-SILVA, J. C.; FELFILI, J. M. (Org.). Cerrado: ecologia, biodiversidade e conservação. Brasília: MMA, 2005. p. 121-139.

SHEPHERD, G. J. FITOPAC 2.1.2. Software. Campinas: Departamento de Botânica, Unicamp, 2010.

SILVA, J. M. C.; BATES, J. M. Biogeographic patterns and conservation in the South American Cerrado: A Tropical Savanna Hotspot. BioScience, Oxford, v. 52, n. 3, p. 225-233, mar. 2002.

SILVA, L. A.; SCARIOT, A. Composição florística e estrutura da comunidade arbórea em uma Floresta Estacional Decidual em afloramento calcário. Acta Botanica Brasilica, Belo Horizonte, v. 17, p. 305-313, 2003.

SILVA, L. A.; SCARIOT, A. Composição e estrutura da comunidade arbórea de uma Floresta Estacional Decidual sobre afloramento calcário no Brasil Central. Revista Árvore, Viçosa, MG, v. 28, p. 69-75. 2004. SILVA, M. P. et al. Distribuição e quantificação de classes de vegetação do Pantanal através de levantamento aéreo. Revista Brasileira de Botânica, São Paulo, v. 23, p. 143-152, 2000.

SIQUEIRA, A. S.; ARAÚJO, G. M.; SCHIAVINI, I. Estrutura do componente arbóreo e características edáficas de dois fragmentos de Floresta Estacional Decidual no vale do rio Araguari, MG, Brasil. Acta Botanica Brasilica, Belo Horizonte, v. 23, p. 10-22, 2009.

SOARES FILHO, A. O. Fitogeografia e estrutura das florestas estacionais deciduais no Brasil. 2012. 346 f. Tese (Doutorado em Botânica) - Feira de Santana, Universidade Estadual de Feira de Santana, 2012. 
SOLÓRZANO, A. et al. Perfil florístico e estrutural do componente lenhoso em seis áreas de cerradão ao longo do bioma Cerrado. Acta Botanica Brasilica, Belo Horizonte, v. 26, p. 328-341, 2012.

SOUZA, P. B. et al. Florística de uma área de cerradão na Floresta Nacional de Paraopeba - Minas Gerais. Cerne, Lavras, v. 16, n. 1, p. 86-93, jan./mar. 2010.

THE PLANT LIST. Versão 1.1. [2013]. Disponível em: <http://www.theplantlist.org>. Acesso em: dez. 2014. 